\title{
An Analysis of the Impact of the "Nearby Enrollment" Policy on Access to Quality Education Resources
}

\author{
Yimin Qian ${ }^{1, *}$
}

\author{
${ }^{1}$ School of political and law University of Jinan \\ *Email:1817452502@qq.com
}

\begin{abstract}
Based on the theory of social exclusion, this paper analyzes the impact of the " Nearby Enrollment " policy on the acquisition of educational resources, and finds that under the effect of the " Nearby Enrollment " policy, the children of families with key schools and high cultural capital in their residence are easy to obtain high-quality educational resources. Families with higher economic and cultural capital can improve their children's access to quality education resources by buying a house and changing their place of residence, or choose to study in private schools to improve the quality of education.
\end{abstract}

Keywords: The policy of " Nearby Enrollment ", High quality education resources, Key schools, Residence

\section{PREFACE}

Since the implementation of the "Compulsory Education Law" in 1986, China has strictly implemented the "Nearby Enrollment" policy. The "Nearby Enrollment" policy not only ensures that students are more convenient to receive the required school education, but also partly slows down the phenomenon of "school choice fever". However, in the context of educational involution, people's desire to possess highquality educational resources only increases. The uneven distribution of educational resources and the socioeconomic status of families are the two major factors affecting the inequality of educational opportunities in China. Under the effect of the "Nearby Enrollment" policy, the two factors affect students' access to quality education opportunities.

\section{LITERATURE REVIEW}

Although the key school system has disappeared, the key school has been active in people's field of vision in the form of model school or experimental school. Under the "Nearby Enrollment" policy, the access to education resources depends on whether there are key schools in the place of residence and the education investment of the local government. As the economic development and the amount of educational resources in residence affect the choice of residents, the government actively increases the investment in educational resources to attract residents. [1-2] key schools are generally distributed near government agencies and institutions. To some extent, the policy of "Nearby Enrollment" reflects the enrollment opportunities based on the distribution of residence, but in fact, it is distributed according to the economic status of families. The choice of education causes the division of capitalization of education services and residence. ${ }^{[3]}$ On the family side, the Coleman report points out that access to educational opportunities and personal economic status are mutually constructed. ${ }^{[4]}$ Class status affects the acquisition of personal cultural capital. Children with higher comprehensive quality are more likely to be favored by high-quality educational resources and achieve higher academic achievement. ${ }^{[5]}$ There are also differences in parental participation and parenting styles among different families. ${ }^{[6]}$ the phenomenon of parent broker is more significant in the dominant class. ${ }^{[7]}$ When the policy of " Nearby Enrollment " is coupled with the real estate market, economic capital gradually becomes the core element of competing for high-quality educational resources and realizing intergenerational reproduction, and forms the interactive circulation and locking mechanism of educational resources, social strata and living space. ${ }^{[8]}$ Private education provides a new way to obtain high-quality education resources, ${ }^{[9]}$ promotes the return of education right from government monopoly to government and society sharing, and teenagers can choose the type and place of schooling independently. ${ }^{[10]}$ Whether or not to get high quality education in the early stage has a decisive impact on the educational diversion of its follow-up education. ${ }^{[1]}$ To sum up, the access to 
high-quality education resources by the "Nearby Enrollment" policy is affected by the residence and family capital, but buying a house and choosing a school and studying in private schools also become a means of access to high-quality education resources. However, the academic literature on the impact of the "Nearby Enrollment" policy on the acquisition of high-quality educational resources is relatively few. This paper will take families with high economic and cultural capital as the research object, and analyze the impact of the "Nearby Enrollment" policy on the acquisition of highquality educational resources from three aspects of regional exclusion, economic exclusion and cultural exclusion from the perspective of social exclusion theory.

\section{REGIONAL EXCLUSION: IS THERE A KEY SCHOOL IN THE RESIDENCE}

Under the policy of "enrollment nearby", regional exclusion is mainly caused by residence. There is no key school in residence, which will seriously affect the access to quality education resources. In China, there are some inertia in resource allocation, such as city center and supporting key schools. Key schools occupy a large amount of national and local government education funds. Families who live in key schools have more opportunities to obtain high-quality education resources. Most of the key schools are located in or close to the center of the city, and the "close to school" policy implicitly selects students through their residence. Basic education resources are public products provided by local governments, which are limited by local government finance. In the basic education market, the local government is the supplier and the family is the demander. The local government provides high-quality education services to the family, while the family provides more taxes to the government. Residents choose to consume public goods by changing their place of residence, while the government attracts high-quality labor force with the help of high-quality education resources to drive local development, which actually forms a mechanism of "voting with feet" ${ }^{[1]}$ It is very difficult for the residents without high-quality education resources to obtain the admission qualification of key schools. The high-quality education resources rely on the scope of residence to form regional exclusion to the source of students.

Under the policy of nearby enrollment, the meaning of proximity is not based on the straight distance of home school, but the reasonable allocation of educational resources within the school district. The spatial division of residential areas caused by cultural, economic and political reasons, while the policy of entrance to the nearby is based on the allocation of educational resources to affect the quality of students' education. In the long run, the quality of education will affect human capital by the quantity of education, in turn, it will intensify the division of living space. Access to high-quality education resources by regional exclusion, mainly in urban and rural differences, key schools are distributed in the city, while the township in the absence of key schools, but also facing the plight of hollowing out schools, rural students in access to high-quality education resources is very difficult.

\section{CULTURAL EXCLUSION: FAMILY CULTURAL CAPITAL INFLUENT ON ADMISSION QUALIFICATION}

Family cultural capital affects children's access to school. At the school level in the study area, there is still room for competition, such as the key level of the school and whether the class is an experimental class. The higher the family cultural capital is, the more chance they have to obtain higher quality education resources. The advantage of family in at least one aspect of capital will increase their children's access to quality education resources. Families with higher social and economic status usually invest more money in the acquisition of educational resources and extracurricular training, and also invest a lot of time in children's educational activities. At the same time, parents will also make use of the superior social network to improve their access to high-quality educational resources. The higher the family cultural capital, the easier the children to inherit the status advantage of their parents. Parents with rich cultural capital pass on higher learning ability and problemsolving ability to their children, so that they can obtain higher academic level. Parents with good cultural literacy and comprehensive quality can create a family environment more conducive to their children's learning, help their children improve their educational expectations, and indirectly accumulate their children's cultural capital.[5] The higher the family economic status is, the more efficiently the cultural capital can be converted into academic achievement. From the perspective of family intergenerational inheritance, the educational background of parents and family capital affect the access to education opportunities and the level of education of children to a certain extent. From the perspective of individual development, the process of education acquisition is a cumulative process. The quality of people's previous education affects people's subsequent education opportunities or academic achievement to a certain extent.

Family capital's educational expectation, academic achievement and comprehensive ability affect the acquisition of high-quality resources. Family cultural capital is mainly affected by parents' educational level. The more educational experience parents have, the more they can help their children improve their human capital. The higher the children's human capital, the greater the chance to obtain high-quality education resources. It is more difficult for children of families whose cultural 
capital is not dominant to obtain high-quality educational resources.

\section{ECONOMIC EXCLUSION: TWO WAYS OF FAMILY EDUCATION INVESTMENT}

Under the "Nearby Enrollment" policy, buying a house to change the place of residence, studying in key schools and studying in private schools are two ways to obtain high-quality education resources through family economic capital. The former flows the school choice fees into the real estate market in the form of house purchase fees, while the latter flows into the education capitalization market.

\subsection{Buy a House, Change Your Residence and Study in a Key School}

High income families make their children obtain high-quality education resources by buying a house and choosing a school. The "Nearby Enrollment" policy has become a compulsory requirement of the government for parents and students, and a means of governing "school selection". In order to resist the "school nearby" policy, families with social and economic advantages increase their children's access to quality education resources by buying a house and changing their residence. With the gradual maturity of the real estate market, strict "Nearby Enrollment" not only cannot bring real equality of opportunity, but also expand the inequality of access to high-quality education opportunities brought by the income gap. When educational resources are allocated through the real estate market, residents choose the residential area and the public goods provided by the government according to their own income and preferences. The quantity and quality of public goods are reflected in the housing price. ${ }^{[1]}$ High income people let their children obtain high-quality basic education resources by buying houses near good schools, which does not have a positive impact on the equal access to education opportunities. On the contrary, it aggravates the housing division according to income and the inequality of education opportunities. The school choice fees that should have been paid to the school flow into the real estate market in the form of house prices, and do not enter the government's education finance. At the same time, buying a house brings heavy pressure on the family economy. Therefore, the way of buying a house to choose a school excludes the families with weak economic capital. High income people live close to high-quality education resources, which drives the local price level to rise, gradually expels the original residents from the places where high-quality education resources are located, makes high-quality education resources occupied by high-income people for a long time.

\subsection{Study in Private Schools}

Since the mid-1990s, China has adopted the efficiency priority mode of combining elitism with education for all, which has the nature of education for all, and private education has gradually emerged. Many private schools are transformed from key schools and have high-quality educational resources. Private schools generally screen students through cooperation with educational institutions, interviews and lottery. Educational institutions can provide performance indicators to private schools, and students who study in educational institutions have priority to enter private schools. At the same time, students can also enter private schools through interviews. Academic level and selfcultivation are important reference indicators for interviews. Based on the above two ways, the students with the advantage of family economic and cultural capital are more likely to obtain the admission qualification of private schools. The number of students who get the entrance qualification by lottery is half less than that by interview, and the actual number of winners is much less than that of those who participate in lottery. It is a safe way for students to get the entrance qualification through interview, but it puts forward requirements for the economic and cultural capital of students' families. Secondly, in the stage of basic education, students in private schools need to pay high tuition fees, and school operation funds come from students' tuition fees and living expenses. Private schools screen students through family economic status. Families with ordinary family economic conditions need to choose carefully whether to study in private schools. Studying in private schools is not restricted by the nearby enrollment policy, but it needs great financial support from families. Generally speaking, there are economic challenges for families to study in private schools.

\section{CONCLUSION AND REFLECTION}

Under the policy of "enrollment nearby", residence plays a decisive role in the acquisition of educational resources, and family capital also affects the acquisition of high-quality educational resources. By buying a house to change the place of residence to study in key schools and private schools, to realize the possession of highquality educational resources is actually to gather the groups with strong homogeneity and exclude the heterogeneous groups in the structure. Under the effect of the "school nearby" policy, the children of families with key schools and high cultural capital are easy to obtain high-quality education resources. Families with higher economic and cultural capital can improve their children's access to quality education resources by buying a house and changing their place of residence, or choose to study in private schools to improve the quality of education. 
The policy of "entering schools nearby" can only restrict the vulnerable groups' freedom of choosing schools and ensure the equality of educational opportunities at the lowest level. There are two main reasons for this phenomenon: first, the distribution of high-quality education resources is uneven and coupled with the residence of the dominant groups. The areas where the dominant groups live usually have better natural and cultural environment and higher quality education resources, while the areas where the disadvantaged groups live do not have such advantages, so they have lower opportunities to study high-quality education resources. Second, under the "Nearby Enrollment" policy, if assigned to weak schools, the dominant groups can choose schools by buying houses or studying in private schools, while the disadvantaged groups can only passively accept the arrangement" Under the effect of the "Nearby Enrollment" policy, the vast majority of high-quality education resources are occupied by the dominant class, and the way of buying a house to study in key schools is only suitable for families with abundant economic and cultural capital. The dominant class forms a small circle, and the disadvantaged groups who live in the areas with highquality education resources will be gradually squeezed out of their residence. The insiders have a high sense of identity with the circle and exclude the outsiders, which further aggravates the uneven distribution of education resources and makes it more difficult to obtain equal opportunities for high-quality education.

\section{REFERENCES}

[1] Feng Hao, Lu Ming. Choosing a school by buying a house: empirical evidence and policy implications of education on housing prices [J]. World economy, 2010,33 (12): 89-104

[2] Fang Changchun. How family background affects education acquisition: from the perspective of residential space differentiation $[\mathrm{J}]$. Journal of education, 2011,7 (06): 118-126

[3] Zheng Lei, Wang Simeng. School selection, capitalization of educational services and residential Division: a reflection on the policy of "admission to nearby schools" [J]. Education and economy, 2014 (06): 25-32.2

[4] COLEMAN, JAMES S. Equality of Education Opportunity[M], Washington D.C.: U.S. Government Printing office, 1966.

[5] Hu Anning. Cultural capital research: Rethinking in Chinese context [J]. Social Sciences, 2017 (01): 6471

[6] Huang Chao. Class differences in parenting styles and their impact on children's non cognitive ability [J]. Society, 2018,38 (06): 216-240
[7] Yang Ke. Brokers of motherhood: changes of motherhood in the context of education marketization [J]. Women's studies, 2018 (02): 79 90

[8] Song Weixuan, Tu Tangqi, Yin Gongzheng, Xu Yan, Liu Chunhui. Study on the difference and effect of social spatial accessibility of compulsory education resources in Nanjing [J]. Geography research, 2019,38 (08): 2008-2026

[9] Zhu Qingmei. Analysis on the influencing factors of private education capital investment in China [J]. Dongyue Lun Cong, 2013,34 (09): 131-135

[10] Wu Hua, Ji Hualei. On the unique contribution of private education to national education development [J]. Journal of East China Normal University (EDUCATION SCIENCE EDITION), 2020,38 (10): 69-77

[11] Wu Yuxiao. Educational diversion system and educational stratification in China (1978-2008) [J]. Sociological research, 2013,28 (04): 179-202 + 245246

[12] Li Zhonglu, Qiu Zeqi. How does family background affect children's academic achievementAnalysis of the differences in the influence of family socioeconomic status in compulsory education [J]. Sociological research, 2016,31 (04): 121-144 + 244245

[13] Wen Dongmao. School choice in urban compulsory education in China and its impact on vulnerable groups [J]. Peking University Education Review, 2006 (02): 12-23 + 189

[14] Yang Dongping. From equal rights to equal opportunities: the path of educational equality in New China $[\mathrm{J}]$. Peking University Education Review, 2006 (02): 2-11 + 189 